\title{
Increased sensitivity and discrimination in screening through an immobilized-resin microbiological assay method
}

\author{
Henry Y. Wang and Jay J. Seaton \\ Department of Chemical Engineering, The University of Michigan, Ann Arbor, MI, U.S.A. \\ Received 17 February 1987 \\ Revised 13 July 1987 \\ Accepted 17 July 1987
}

Key words: Bioassay; Polymeric resin; Bioscreening; Antibiotic

\section{SUMMARY}

Problems with present bioactive microbial product screening techniques include low sensitivity and insufficient discrimination capabilities. These problems are addressed by our new immobilized-resin microbiological assay. This technique concentrates bioactive samples on macroporous polymeric resins that are immobilized in hydrogel beads. These beads are then subjected to elution in the wells of an agar diffusion microbiological assay medium. With a strong base anion exchanger, the sensitivity to ampicillin of the $\beta$ lactam-supersensitive Escherichia coli mutant ESS-22-31 was increased 10-fold. Similar increases in sensitivity were obtained in the detection of streptomycin using a weak acid cation exchanger with Bacillus subtilis and for cycloheximide by a neutral resin and Saccharomyces cerevisiae NRRL-Y-139. A judicious choice of resin type and eluent permitted a selective sensitivity increase based on the charge or hydrophobic nature of the desired product. This selectivity imparts a discrimination capability to the technique

\section{INTRODUCTION}

Fermentation screening programs are widely applied in the search for useful bioactive products [3]. The performance of any screening program is directly dependent on the method used to detect the compound of interest. The method of detection is often an agar diffusion-type microbiological assay. In this method samples are placed on the surface of an agar plate that has been seeded with a suitable assay organism. The sample is then allowed to dif-

Correspondence: H.Y. Wang, Department of Chemical Engineering, The University of Michigan, Ann Arbor, MI 481092136, U.S.A. fuse through the agar as the plate is incubated. In the case of an antibiotic sample, zones of inhibited growth will surround the point of sample application. Traditional methods for application of samples to the surface of the agar involve the use of cylindrical holes bored in the agar, stainless steel or porcelain cylinders set on the surface, or filter paper discs to which small amounts of sample have been added [4]. Any improvements in this assay method should be reflected in improved screening results.

Improvements in two problem areas of agar diffusion microbiological assays, sensitivity and discrimination, are especially beneficial to screening. Since any bioactive compounds that are present in 
a sample at concentrations below the threshold concentration of the assay are simply not detected, any increases in sensitivity should increase the number of useful compounds discovered. Improvements in the discrimination ability, sometimes termed selectivity, of the assay can ease the screening workload by allowing investigators to concentrate their efforts on one particularly promising group of compounds. One approach to improvements in these areas has been the development of test organisms that are supersensitive to solely $\beta$-lactam antibiotics while retaining their normal sensitivities to other antibiotics [5,6].

An alternative approach to increasing the sensitivity of the agar diffusion microbiological assay has been developed by Wang and co-workers $[8,12]$. The technique, termed a resin-based microbiological assay, replaces the traditional means of applying the samples to the assay plates with the use of macroporous polymeric resins. The neutral adsorbent resins employed are available in the $20-50$ mesh size range and have both high porosities and high surface areas [12]. The resin-based assay technique takes advantage of the resin's ability to adsorb and concentrate hydrophobic antibiotics from solution by means of van der Waals forces. After adsorption has occurred, the resin particle is eluted in the well of a bioassay plate. Cationic and anionic macroreticular ion exchange resins capable of concentrating charged species from solution, through ionic interactions, are also available.

Reported here is an analysis which identifies the important parameters effecting the large sensitivity increase obtainable using the resin-based assay technique, the extension of the technique to the detection of charged species through the use of ion exchange resins, and the discrimination capabilities which arise from a judicious choice of resin type and eluent.

\section{MATERIALS AND METHODS}

Test organism inoculum and plate preparation for the agar-diffusion assay

Cycloheximide assay. The test organism for the detection of cycloheximide was Saccharomyces cerevisiae NRRL-Y-139 (Northern Regional Research Laboratory, Peoria, IL). The test organism inoculum was prepared as a 24-h liquid culture of $S$. cerevisiae Y-139 with full viability.

The bioassay medium contained the same ingredients as that for the paper-disc plate method for cycloheximide [14]. After heating to dissolve the agar, the medium was sterilized for $15 \mathrm{~min}$ at $121^{\circ} \mathrm{C}$. After cooling of this medium to $47^{\circ} \mathrm{C}$ a $0.5 \mathrm{vol} \%$ addition of the test organism inoculum was made. Ten-milliliter aliquots of this medium were dispensed into 85 -mm-diameter plates. These assay plates were then refrigerated in sealed bags and the plates were used within 2 weeks.

Vitamin $B_{12}$ assay. The test organism for the detection of vitamin $\mathbf{B}_{12}$ was Lactobacillus leichmannii ATCC 7830. Test organism inoculum was prepared from the stab cultures in $10 \mathrm{ml}$ of BatoMicro Inoculum Broth (Difco, Detroit, MI) by incubating for $20 \mathrm{~h}$ at $36^{\circ} \mathrm{C}$. The cells were aseptically centrifuged and washed with isotonic $\mathrm{NaCl}$ solution twice and resuspended in $10 \mathrm{ml}$ of sterile isotonic $\mathrm{NaCl}$ solution. The vitamin $\mathrm{B}_{12}$ agar bioassay medium consisted of $90^{\circ} \mathrm{g}$ Bacto C.S. Vitamin $\mathrm{B}_{12}$ Agar (Difco, Detroit, MI) in 1 liter of distilled $\mathrm{H}_{2} \mathrm{O}$. After sterilization and cooling the medium to $47^{\circ} \mathrm{C}$, a $1.0 \mathrm{vol} \%$ prepared test organism inoculum was added. Twenty-milliliter aliquots of this seeded medium were dispensed into 85-mm-diameter plates.

Streptomycin assay. The test organism for the detection of Streptomycin was Bacillus subtilis BEL-1 (University of Michigan, Ann Arbor, MI). The stock inoculum of B. subtilis BEL-1 for use in the streptomycin assay was prepared on the surface of an agar medium. Composition of the medium and conditions of preparation were as suggested in the U.S. Pharmacopeia [11].

The streptomycin agar bioassay medium consisted of $23 \mathrm{~g}$ of nutrient agar (Difco Labs, Detroit, MI) in 1 liter of distilled $\mathrm{H}_{2} \mathrm{O}$. After heating to dissolve the agar, the medium was sterilized for $15 \mathrm{~min}$ at $121^{\circ} \mathrm{C}$. After cooling of this medium to $47^{\circ} \mathrm{C}$, a $0.01 \mathrm{vol} \%$ addition of the test organism inoculum was made. Ten-milliliter aliquots of the seeded medium were dispensed into 85 -mm-diameter plates. 
Ampicillin assay. One test organism used for the detection of ampicillin was Staphylococcus aureus B-313 (The University of Michigan, Ann Arbor, MI). The test organism inoculum was prepared as a 24-h liquid culture of $S$. aureus B-313.

The agar bioassay medium for ampicillin using $S$. aureus B-313 consisted of $23 \mathrm{~g}$ of nutrient agar (Difco Labs, Detroit, MI), $2 \mathrm{~g}$ of yeast extract and 1 liter of distilled $\mathrm{H}_{2} \mathrm{O}$. After heating to dissolve the agar, the medium was sterilized for $15 \mathrm{~min}$ at $121^{\circ} \mathrm{C}$. After cooling to $47^{\circ} \mathrm{C}$, a $0.8 \mathrm{vol} \%$ addition of the test organism was made. Ten-milliliter aliquots of this seeded medium were dispensed into $85-\mathrm{mm}$ diameter plates.

An additional test organism used for the detection of ampicillin was Escherichia coli ESS-22-31, a $\beta$-lactam-supersensitive mutant (A. Demain, M.I.T., MA). The test organism inoculum was prepared as a 20 -h liquid culture.

The agar bioassay medium for the detection of ampicillin using E. coli ESS-22-31 consisted of 23 $\mathrm{g}$ of nutrient agar (Difco Labs, Detroit, MI) in 1 liter of distilled $\mathrm{H}_{2} \mathrm{O}$. After heating to dissolve the agar, the medium was sterilized for $15 \mathrm{~min}$ at $121^{\circ} \mathrm{C}$. After cooling to $47^{\circ} \mathrm{C}$, a $3.0 \mathrm{vol} \%$ addition of the test organisms was made. Ten-milliliter aliquots of this seeded medium were dispensed into $85-\mathrm{mm}$ diameter plates.

Antibiotic solutions. To prepare the cycloheximide aqueous standards, pure cycloheximide (Upjohn, Kalamazoo, MI) was dissolved in distilled $\mathrm{H}_{2} \mathrm{O}$. The streptomycin solutions were prepared by dissolving streptomýcin sulfate (Pfizer, New York, $\mathrm{NY}$ ) in a phosphate buffer composed of $16.73 \mathrm{~g} / 1$ $\mathrm{K}_{2} \mathrm{HPO}_{4}$ and $0.523 \mathrm{~g} / \mathrm{KH}_{2} \mathrm{PO}_{4}$ with the $\mathrm{pH}$ adjusted to 8 by $18 \mathrm{~N}$ phosphoric acid.

The ampicillin solutions were prepared by dissolving sodium ampicillin (Upjohn, Kalamazoo, MI) in the phosphate buffer described above.

\section{Resin preparation and immobilization}

The macroreticular resins employed were prepared by first grinding the resin to a fine powder with a mortar and pestle. The ground neutral adsorbent resin XAD-4 (Rohm and Haas, Philadelphia, PA) was then soaked in methanol before being rinsed in distilled $\mathrm{H}_{2} \mathrm{O}$. The ground ion exchange resins IRC-50 and IRA-938 (Rohm and Haas, Philadelphia, PA) were placed in their proper ionic forms by repeated washings with $1.5 \mathrm{~N}$ $\mathrm{NaOH}, 2 \mathrm{~N} \mathrm{HCl}$, and distilled $\mathrm{H}_{2} \mathrm{O}$ before being stored in distilled water.

The prepared and powdered resins (to make up $10 \mathrm{wt} \%$ of the final bead volume) were added to a hot $4 \%(\mathrm{w} / \mathrm{v})$ solution of $\mathrm{K}$-carrageenan or agarose (FMC Corporation, Marine Colloids Division, Springfield, NJ) which had been autoclaved at $121^{\circ} \mathrm{C}$ for $15 \mathrm{~min}$. The resulting mixture was pumped through small tubing into a $2 \% \mathrm{KCl}$ solution. $2 \% \mathrm{KOH}$ was used for the anion exchange resin in the $\mathrm{OH}^{-}$form. The resulting spherical beads were approximately $3 \mathrm{~mm}$ in diameter and about $10 \mathrm{wt} \%$ resin. Plain beads were prepared by omitting the addition of powdered resin.

\section{Immobilized-resin microbiological assay}

One immobilized resin bead containing either XAD-4, IRC-50, or IRA-938 was placed in a screwcapped sample vial along with $5 \mathrm{ml}$ of test sample. These vials were then shaken in a $25^{\circ} \mathrm{C}$ incubation room on a rotary shaker $(300 \mathrm{rpm})$ for $6 \mathrm{~h}$. At the end of the $6-\mathrm{h}$ period the immobilized resin beads were removed from the vials and dried with a paper towel.

A single immobilized resin bead was placed in the previously cut well of an assay plate appropriate for the compound to be detected. $0.05 \mathrm{ml}$ of $5 \mathrm{M}$ $\mathrm{NaCl}$ or $0.05 \mathrm{ml}$ of $95 \mathrm{vol} \% \mathrm{EtOH}$ was then added to the wells containing ion exchange or neutral adsorbent immobilized resin beads, respectively. The cycloheximide assay plates were incubated at $25^{\circ} \mathrm{C}$ for $24 \mathrm{~h}$. The streptomycin assay plates were incubated at $33^{\circ} \mathrm{C}$ for $20 \mathrm{~h}$. The $E$. coli plates for the detection of ampicillin were incubated at $37^{\circ} \mathrm{C}$ for $20 \mathrm{~h}$ and the $S$. aureus plates for $24 \mathrm{~h}$ at $37^{\circ} \mathrm{C}$. The inhibition zones that resulted were read with the use of a Fischer-Lilly antibiotic zone reader.

\section{Paper disc agar diffusion assay}

1.25-cm-diameter analytical paper circles (Schleicher and Schuell, Keene, NH) were used in the paper disc assay. $0.1 \mathrm{ml}$ of test sample was 
added to a disc which was then placed on the surface of an assay plate. Incubation temperatures and times were identical to those employed in the immobilized-resin-based assays.

\section{RESULTS AND DISCUSSION}

Immobilized-resin assays for hydrophobic and charged compounds

We examined the ability of the free-resin-based assay technique to increase the detection capabilities, or sensitivity, of the agar-diffusion microbiological assay for both a growth-inhibiting compound (cycloheximide) [8] and a growth factor, vitamin $B_{12}$ (Figs. 1 and 2). Both of these compounds are hydrophobic in nature. The significant difference between the assays was the development of growth (exhibition) zones around the point of ap plication for $B_{12}$ as compared to the inhibition zones that were formed in the cycloheximide assay. However, many useful bioactive compounds are not hydrophobic but rather possess either a net negative or a net positive charge. These species will

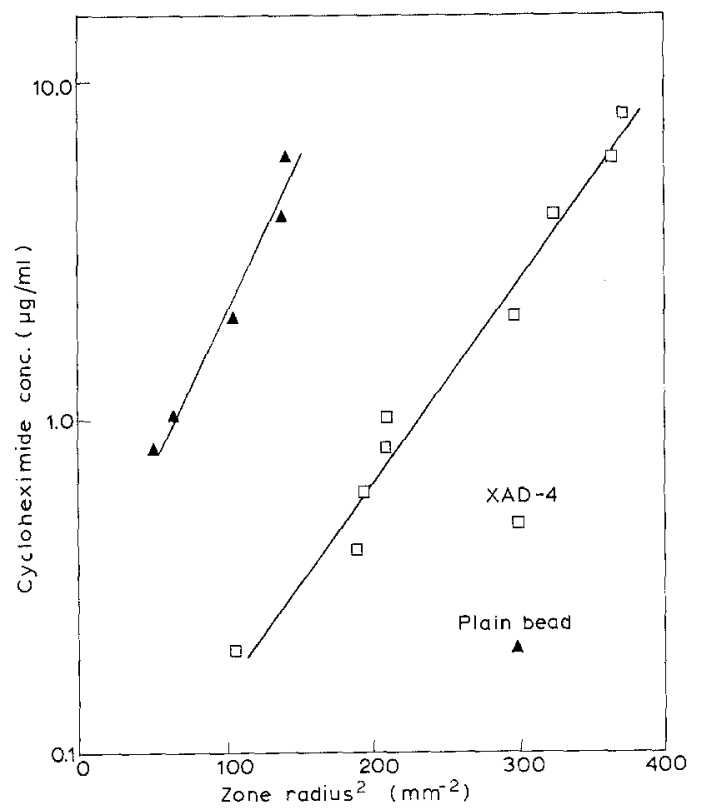

Fig. 1. Cycloheximide concentration as a function of inhibition zone radius squared for an XAD-4 imobilized-resin assay (plain bead as control).

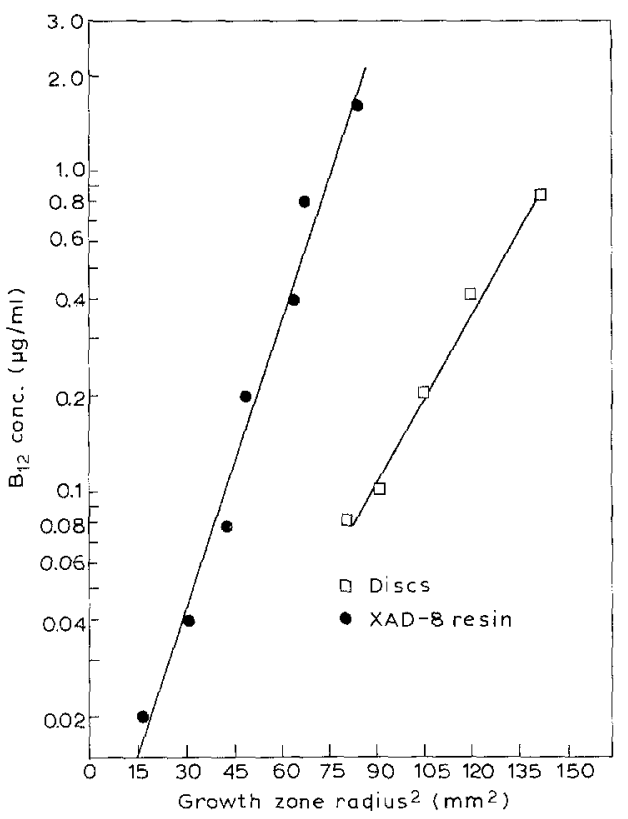

Fig. 2. Vitamin $B_{12}$ concentration as a function of growth zone radius squared for $\mathrm{XAD}-8$ resin assay (paper disc as control).

not adsorb to any appreciable extent on the neutral adsorbent resins used in the assays for cycloheximide and $B_{12}$. The characteristic charge of many antibiotics, as determined by electrophoretic studies, has been used as a means of categorization [10]. Charged species such as these are readily adsorbed onto ion exchange resins.

Similar results can be shown when applying the immobilized-resin assay technique to the assay of streptomycin and ampicillin. The assay for cycloheximide, a hydrophobic compound, utilized the neutral adsorbent resin XAD-4 with ethanol as the eluent. The tri-basic streptomycin was assayed using the cation exchanger IRC-50 and $5 \mathrm{M} \mathrm{NaCl}$ as an eluent. The weak base anion exchanger IRA-938 and $5 \mathrm{M} \mathrm{NaCl}$ were employed in the assay for ampicillin. A linear relationship between logarithmic concentration and zone radius squared, consistent with inhibition zone theory, was found in all three cases.

Quantitative description of this assay

The resin-based assay technique is based on utilizing polymeric adsorbents or ion exchange resins instead of filter paper discs as the means of applying 
samples to a bioassay plate. Since these resins are able to adsorb and concentrate antibiotics from solution, elution of the antibiotic previously adsorbed on the resin by eluting agents such as ethanol or concentrated $\mathrm{NaCl}$ solutions results in an antibiotic concentration on the plate that is greater than the direct application of an unconcentrated sample.

Adsorption of dilute organic compounds onto polymeric resins has been shown to follow Freundlich-type adsorption isotherms:

$C^{*}=b\left(Q_{n}\right)^{a}$

where $C^{*}=$ equilibrium concentration in the bulk solution $(\mathrm{mg} / \mathrm{ml}), Q_{\mathrm{n}}=$ resin $(\mathrm{mg} / \mathrm{g}$ of resin), and $a, b=$ empirical constants for both neutral adsorbent [13] and ion exchange [1] type resins.

The sensitivity increases obtainable with the resin-based assay technique arise from the concentration effect of the resin. A concentrating factor indicative of the sensitivity increase obtained can be defined as:

$K=C_{\mathrm{E}} / C_{0}$

where $C_{\mathbf{E}}=$ concentration in the eluting solution and $C_{0}=$ original concentration in the sample solution.

A material balance done after equilibration of a resin bead with a sample of constant total antibiotic content shows that:

$C_{0}=\frac{W_{\mathrm{R}} Q_{\mathrm{R}}+C^{*} V_{\mathrm{s}}}{V_{\mathrm{s}}}$

where $W_{\mathrm{R}}=$ weight of resin employed $(\mathrm{g})$ and $V_{\mathrm{s}}$ $=$ volume of sample with which the resin was equilibrated.

While a material balance on the elution of the resin in the well of the assay plate shows:

$C_{\mathrm{E}}=Q_{\mathrm{n}}\left(W_{\mathrm{R}} / V_{\mathrm{E}}\right) \varepsilon$

where $V_{\mathrm{E}}=$ volume of eluent and $\varepsilon=$ extraction efficiency.
The extraction efficiency $(\varepsilon)$ must be included to account for the possibility that not all of the antibiotic adsorbed on the resin may be removed by the addition of the eluting agent. Substitution of Eqns. 1,3 and 4 into 2 yields:

$K=\frac{V_{\mathrm{s}}}{V_{\mathrm{E}}} \frac{W_{\mathrm{R}}}{W_{\mathrm{R}}+b Q_{\mathrm{na}}-1 V_{\mathrm{s}}} \varepsilon$

Eqn. 5 identifies several important and adjustable quantities that determine the concentrating factor, and thus the sensitivity-improvement capabilities, of the resin-based assay technique. These quantities are the ratio of the sample volume to eluent volume, the weight of resin along with its loading characteristics, and the extraction efficiency of the elution step. $K$ for the case of cycloheximide and XAD-4 resin can easily fall in the range of $10^{2}-10^{3}$. The extraction efficiency $(\varepsilon)$ is not totally independent of the volume of eluent $\left(V_{\mathrm{E}}\right)$ since increasing $\varepsilon$ may require that a greater amount of eluting solution be added to the well. However, through repeated additions of a volatile eluent, such as $\mathrm{EtOH}$, we have been able to increase $\varepsilon$ without increasing the volume of eluent present in the well at any given time.

The immobilized-resin assay technique utilizes ground resins that are immobilized in a hydrogel matrix. This polymer has been extensively used for the immobilization of enzymes and microbial cells [9]. The immobilized system permits the use and subsequent retrieval of small ground resin particles that would have been difficult to recover had they been employed as free suspended resin particles. Ground immobilized resins also exhibit reduced internal diffusional resistance, as compared to normal sized resins, that leads to increased adsorption rates and may aid in elution [13]. Hydrogel immobilization also permits the co-immobilization of magnetic particles to aid in later bead retrieval. Co-immobilization of magnetic particles with microororganisms and the use of magnetic supports have been reported in the literature $[2,7]$.

Table 1 summarizes the sensitivity increases obtained using the immobilized-resin assay technique. The lowest detectable antibiotic concentration was 
Table 1

Summary of sensitivity increase ${ }^{a}$ attained

\begin{tabular}{|c|c|c|c|c|}
\hline Antibiotic & Test organism & Assay type & $\begin{array}{l}\text { Detection limit } \\
(\mu \mathrm{g} / \mathrm{ml})\end{array}$ & Increase \\
\hline Cycloheximide & S. cerevisiae & $\begin{array}{l}\text { paper disc } \\
\text { plain bead } \\
\text { A-377 } \\
\text { IRC-50 } \\
\text { XAD-4 }\end{array}$ & $\begin{array}{l}0.8 \\
0.6 \\
0.4 \\
0.5 \\
0.06\end{array}$ & $\begin{array}{r}- \\
1.3 \\
2.0 \\
1.6 \\
13.3\end{array}$ \\
\hline Streptomycin & B. subtilis & $\begin{array}{l}\text { paper disc } \\
\text { plain bead } \\
\text { XAD-4 } \\
\text { A-377 } \\
\text { IRC-50 }\end{array}$ & $\begin{array}{l}1.0 \\
3.5 \\
3.5 \\
3.5 \\
0.5\end{array}$ & $\begin{array}{l}- \\
0.3 \\
0.3 \\
0.3 \\
2.0\end{array}$ \\
\hline Ampicillin & S. aureus & $\begin{array}{l}\text { paper disc } \\
\text { plain bead } \\
\text { IRA-938 (Cl cycle) } \\
\text { IRA-938 (OH cycle })\end{array}$ & $\begin{array}{l}0.2 \\
0.1 \\
0.035 \\
0.012\end{array}$ & $\begin{array}{r}- \\
2.0 \\
5.7 \\
16.7\end{array}$ \\
\hline
\end{tabular}

${ }^{\text {a }}$ Sensitivity increase $=\frac{\text { paper disc detection limit }}{\text { resin assay detection limit }}$

used as a measure of sensitivity. Significant increases in sensitivity, as compared to the filter paper disc assay method, were obtained using the resin-based technique.

For the case of cycloheximide with XAD-4 neutral adsorbent resin, Eqn. 5 predicts that the experimental conditions used should yield a concentration factor of approximately 98 , if the extraction efficiency term is at its maximum value of 1 . The observed sensitivity increase of 13 suggests that the maximum capabilities of the assay have not been achieved. The cause of the discrepancy is an actual extraction efficiency of less than 1. Since K-carrageenan is a sulfonated polysaccharide, it may act as an ion-exchanger, thus reducing the sensitivity limit in some instances, as in the case of streptomycin. By switching to agarose as immobilization matrix, the sensitivity for streptomycin can also be increased (data not shown).

As noted in the introduction, $\beta$-lactam-supersensitive organisms have been used to increase the sensitivity and specificity of screening toward $\beta$-lactam antibiotics. E. coli ESS-22-31 is one such organism that is specifically sensitive for $\beta$-lactams. Use of this assay organism with IRA-938 anion exchange resin in the resin-based assay technique resulted in an increase in sensitivity of 25 as compared to the filter paper disc assay. Since the resin-based assay depends on the concentrating effect of the resin, increases in assay sensitivity based on developing even more highly sensitive strains can be increased further by coupling the supersensitive organism to the immobilized-resin assay technique. The sensitivity increases shown in Table 1 occurred only for the particular combination of antibiotic and resin type listed. Use of either of the other two resin types with a given antibiotic resulted in no appreciable sensitivity increase. This selective sensitivity increase is based on the charge or hydrophobic nature of the antibiotic and imparts a discrimination capability to the technique. The use of all three resin types along with plain hydrogel beads should give a unique inhibition zone formation pattern in the presence of several types of antibiotic mixtures. Fig. 3 shows the inhibition pattern that could result from use of such a resin spectrum. Each column represents a test sample that contains either a single antibiotic compound or a mixture of compounds. 


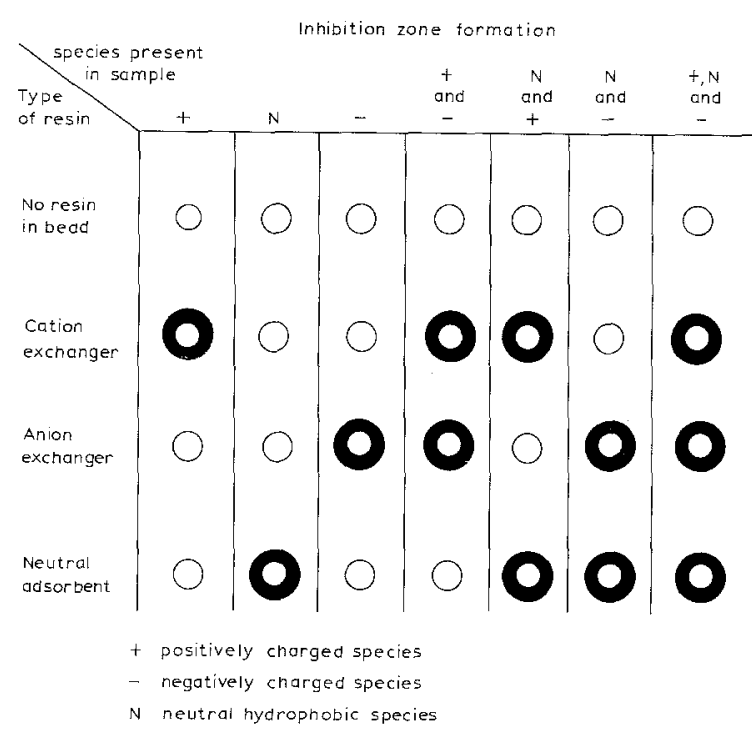

Fig. 3. Discrimination scheme for the resin-based assay to identify new bioactive compounds.

The types of antibiotics present are denoted by $(\mathrm{N})$ for a neutral species sufficiently hydrophobic to result in increased sensitivity when a neutral resin is used and by $(+)$ or $(-)$ to indicate a positively or negatively charged species which results in increased zone sizes when cationic or anionic resins are employed. The zones of inhibition produced with the use of a certain type of resin or plain hydrogel beads are represented by darkened zones. Each case shown has a unique inhibition zone pattern that can indicate the presence of more than one compound and the charge or hydrophobic character of that compound. The patterns predicted in Fig. 1 are for assays in which all compounds are at concentrations such that the volume of antibiotic solution trapped in the hydrogel beads produces no inhibition zone. However, the same type of patterns could result at higher concentrations. In this case, small inhibition zones would be present where there were none at lower concentrations and markedly larger zones would fall into the patterns of Fig. 1.

\section{ACKNOWLEDGEMENT}

The authors would like to acknowledge National Science Foundation research grants (CPE-8010868 and CPE-8406686) for making this work possible.

\section{REFERENCES}

1 Belter, P.A., F.L. Cunningham and J.W. Chen. 1973. Development of a recovery process for novobiacin. Biotechnol. Bioeng. 15: 533-549.

2 Halling, P.J. and P. Dunnill. 1980. Magnetic supports for immobilized enzymes and bioaffinity adsorbents. Enzyme Microb. Technol. 1977. 2: 2-10.

3 Hamill, R.L. General approaches to fermentation screening. 1977. Japan J. Antibiot. 30 (Suppl.): S164-S173.

4 Hewitt, H. 1977. Microbiological Bioassay. Academic Press, New York.

5 Katano, K. 1983. Recent progress in the discovery of $\beta$-lactam antibiotics. Prog. Ind. Microbiol. 17: 37-69.

6 Katano, K., K. Nara and Y. Nakao. 1977. Screening for $\beta$ lactam antibiotics using a mutant of Pseudomonas aeruginosa. Japan J. Antiobiot. 30 (Suppl): S293-S245

7 Larsson, P.O., S. Birnbaum and K. Mosback. 1981. Magnetic immobilized microorganisms. Adv. Biotechnol. 1: 717-720.

8 Seaton, J.J. and H.Y. Wang, 1983. Fermentation monitoring by polymeric-resin-based microbial assay. Biotechnol. Bioeng. 25: 771-779.

9 Tosa, T., T. Sato, T. Mori, K. Yamamoto, I. Takata, Y. Nishida and I. Chibata. 1979. Immobilization of enzymes and microbial cells using carrageenan as matrix. Biotechnol. Bioeng. 25: 1697-1709.

10 Umegawa, H. and S. Kondo. 1975. Electrophoresis of antibiotics. Methods Enzymol. 43: 279-290.

11 United States Pharmacopeia. Biological Tests and Assay, XIX Revision: 595-600.

12 Wang, H.Y. 1981. Application of polymeric resins as means in microbiological assay. Dev. Ind. Microbiol. 22: 739-779.

13 Wang, H.Y. and K. Sobnosky. 1984. Design of a new affinity adsorbent for biochemical product recovery. In: ACS Symposium Series in Recovery and Purification Process for Fermentation Products (Leakey, T., ed.), in press.

14 Whiffen, A.J. 1948. The production, assay, and antibiotic activity of actidione, an antibiotic from Streptomyces griseus. J. Bacteriol. 56: 283-291. 